\title{
Effect of Food on the Pharmacokinetic Profile of Etamicastat (BIA 5-453)
}

\author{
Manuel Vaz-da-Silva, ${ }^{1}$ Teresa Nunes, ${ }^{1}$ José F. Rocha ${ }^{1}$ Amilcar Falcão, ${ }^{2}$ Luis Almeida ${ }^{3}$ \\ and Patricio Soares-da-Silva ${ }^{1,4}$
}

1 Department of Research and Development, BIAL-Portela \& Co., SA, S. Mamede do Coronado, Portugal

2 Faculty of Pharmacy \& CNC, University of Coimbra, Coimbra, Portugal

3 Health Sciences Section, University of Aveiro, Aveiro, Portugal

4 Department of Pharmacology and Therapeutics, Faculty of Medicine, University of Porto, Porto, Portugal

\section{Abstract}

Background: Etamicastat is a novel, potent, and reversible peripheral dopamine$\beta$-hydroxylase inhibitor that has been administered orally at doses up to $600 \mathrm{mg}$ once daily for 10 days to male healthy volunteers and appears to be well tolerated.

Objective: The aim of this study was to investigate the effect of food on the pharmacokinetics of etamicastat.

Material and Methods: A single-center, open-label, randomized, two-way crossover study in 12 healthy male subjects was performed. Subjects were administered a single dose of etamicastat $200 \mathrm{mg}$ following either a standard high-fat and high-calorie content meal (test) or 10 hours of fasting (reference). The statistical method for testing the effect of food on the pharmacokinetic parameters of interest was based upon the $90 \%$ confidence interval (CI) for the test/reference geometric mean ratio (GMR). The parameters of interest were maximum plasma concentration $\left(\mathrm{C}_{\max }\right)$, area under the plasma concentration-time curve (AUC) from time zero to the last measurable concentration $\left(\mathrm{AUC}_{\text {last }}\right)$, and $\mathrm{AUC}$ from time zero to infinity $\left(\mathrm{AUC}_{\infty}\right)$. Bioequivalence was assumed when the $90 \%$ CI fell within the recommended acceptance interval $(80,125)$.

Results: Etamicastat $\mathrm{C}_{\max }, \mathrm{AUC}_{\text {last }}$, and $\mathrm{AUC}_{\infty}$ were $229 \mathrm{ng} / \mathrm{mL}, 1856 \mathrm{ng} \bullet \mathrm{h} / \mathrm{mL}$, and $2238 \mathrm{ng} \bullet \mathrm{h} / \mathrm{mL}$, respectively, following etamicastat in the fasting, and $166 \mathrm{ng} / \mathrm{mL}, 1737 \mathrm{ng} \bullet \mathrm{h} / \mathrm{mL}$, and $2119 \mathrm{ng} \bullet \mathrm{h} / \mathrm{mL}$, respectively, following etamicastat in the fed condition. Etamicastat test/reference GMR was $72.27 \%$ $(90 \%$ CI $64.98,80.38)$ for $\mathrm{C}_{\max }, 93.59 \%\left(90 \%\right.$ CI 89.28, 98.11) for $\mathrm{AUC}_{\text {last }}$, and $96.47 \%(90 \% \mathrm{CI} 91.67,101.53)$ for $\mathrm{AUC}_{\infty}$. Time to $\mathrm{C}_{\max }$ was prolonged by the presence of food $(\mathrm{p}<0.001)$. The $\mathrm{C}_{\max }, \mathrm{AUC}_{\text {last }}$, and $\mathrm{AUC}_{\infty}$ values of the inactive metabolite BIA 5-961 were $275 \mathrm{ng} / \mathrm{mL}, 1827 \mathrm{ng} \bullet \mathrm{h} / \mathrm{mL}$, and $2009 \mathrm{ng} \bullet \mathrm{h} / \mathrm{mL}$, respectively, in the fasting, and $172 \mathrm{ng} / \mathrm{mL}, 1450 \mathrm{ng} \bullet \mathrm{h} / \mathrm{mL}$, and $1677 \mathrm{ng} \bullet \mathrm{h} / \mathrm{mL}$, respectively, in the fed condition. BIA 5-961 test/reference GMR was $62.42 \%$ 
(90\% CI 56.77, 68.63) for $\mathrm{C}_{\max }, 79.41 \%\left(90 \%\right.$ CI 56.77, 68.63) for $\mathrm{AUC}_{\text {last }}$, and $83.47 \%(90 \%$ CI $76.62,90.93)$ for $\mathrm{AUC}_{\infty}$. A total of six mild to moderate unspecific adverse events were reported by four subjects. There was no clinically significant abnormality in laboratory assessments.

Conclusion: Etamicastat was well tolerated. The $\mathrm{C}_{\max }$ of etamicastat decreased $28 \%$ following oral administration of etamicastat in the presence of food, while AUC remained within the pre-defined acceptance interval. The delay in absorption and decrease in peak exposure of etamicastat is not clinically significant, and therefore etamicastat could be administered without regard to meals.

Trial Registration: EudraCT No. 2007-006530-33

\section{Introduction}

Activation of the sympathetic nervous system is an important feature in hypertension and congestive heart failure. ${ }^{[1-6]}$ Inhibition of sympathetic nerve function with adrenoceptor antagonists appeared to be a promising approach, but a significant proportion of patients do not tolerate the immediate hemodynamic deterioration that accompanies $\beta$-adrenoceptor antagonist ( $\beta$-blocker) treatment, particularly in heart failure patients. ${ }^{[7]}$ An alternative approach for directly modulating sympathetic nerve function is to reduce the biosynthesis of noradrenaline via inhibition of dopamine- $\beta$-hydroxylase $(\mathrm{D} \beta \mathrm{H}){ }^{[8]} \mathrm{D} \beta \mathrm{H}$ is a copper II ascorbate-dependent mono-oxygenase that catalyses the conversion of dopamine into noradrenaline in the catecholamine biosynthetic pathway. The inhibition of $\mathrm{D} \beta \mathrm{H}$ has several putative advantages over adrenoceptor blockade by conventional adrenoceptor antagonists (pure $\beta$-blockers or mixed $\alpha, \beta$-blockers), such as gradual sympathetic modulation as opposed to abrupt inhibition, and causing increased availability of dopamine, which can improve renal function. ${ }^{[8]}$

Several D $\beta H$ inhibitors have been described. Early first- and second-generation examples, such as disulfiram ${ }^{[9]}$ and diethyldithiocarbamate ${ }^{[10]}$ or fusaric acid ${ }^{[11]}$ and aromatic or alkyl thioureas, ${ }^{[12]}$ were found to be of low potency, exhibited poor selectivity for $\mathrm{D} \beta \mathrm{H}$, and caused toxic side effects. A third-generation $\mathrm{D} \beta \mathrm{H}$ inhibitor (nepicastat $[\text { RS-25560-197] })^{[8]}$ was found to have much greater potency and was developed to early clinical trials. Although devoid of some of the problems associated with first- and second-generation $\mathrm{D} \beta \mathrm{H}$ inhibitors, nepicastat was found to cross the blood-brain barrier, and was thereby able to cause undesired and potentially significant CNS-related adverse events. Therefore, to date, there remains an unmet clinical need for a potent, safe, and peripherally selective $\mathrm{D} \beta \mathrm{H}$ inhibitor, which could be used for the treatment of certain cardiovascular disorders without significant adverse events.

Etamicastat [BIA 5-453; (R)-5-(2-aminoethyl)1-(6,8-difluorochroman-3-yl)-1,3-dihydroimidazole-2-thione hydrochloride; molecular formula $\mathrm{C} 14 \mathrm{H} 16 \mathrm{ClF} 2 \mathrm{~N} 3 \mathrm{OS}]$ was designed by BIAL-Portela \& Co., S. Mamede do Coronado, Portugal, to act as a reversible inhibitor of peripheral $\mathrm{D} \beta \mathrm{H} .{ }^{[13]}$ In contrast to that found in the peripheral tissues, etamicastat does not affect dopamine or noradrenaline levels in the brain, ${ }^{[13]}$ which is unique among $\mathrm{D} \beta \mathrm{H}$ inhibitors previously tested for the treatment of cardiovascular disorders.

Etamicastat was tested in animal models predictive of efficacy in cardiovascular disorders. ${ }^{[14-16]}$ Etamicastat reduced systolic and diastolic blood pressure in spontaneously hypertensive rats with no changes in normotensive Wistar-Kyotos rats. ${ }^{[14,15]}$ Etamicastat did not affect heart rate in spontaneously hypertensive or Wistar-Kyotos rats. Etamicastat increased survival rates in male cardiomyopathic hamsters (Bio TO-2 dilated strain) with advanced congestive heart failure. ${ }^{[16]}$ In toxicologic studies, the no observed adverse effect 
level was $5 \mathrm{mg} / \mathrm{kg} /$ day in dogs, $20 \mathrm{mg} / \mathrm{kg} /$ day in Cynomolgus monkeys, and $30 \mathrm{mg} / \mathrm{kg} / \mathrm{day}$ in rats and mice. ${ }^{[17]}$

The metabolism of etamicastat appears to be species dependent. ${ }^{[18]}$ In the rat, N-acetylation appears to be the major metabolic pathway leading to the formation of BIA 5-961, which is inactive. All other metabolites were found to occur in minor amounts and correspond to oxidative deaminated (BIA 5-965), C-oxidated (BIA 5-998), and N-oxidated (BIA 5-1016) derivatives of etamicastat. In an entry-into-man study ${ }^{[19]}$ in healthy subjects administered with single oral doses of etamicastat ranging from 2 to $1200 \mathrm{mg}$, maximum plasma etamicastat concentrations occurred at 1-3 hours post-dose. Elimination was biphasic, characterized by a first short early elimination half-life $\left(t_{1 / 2}\right)$, followed by a longer elimination phase of 16-20 hours for etamicastat doses of $\geq 100 \mathrm{mg}$. Etamicastat underwent $\mathrm{N}$-acetylation to its inactive metabolite BIA 5-961. The other putative metabolites did not appear in plasma or urine. In a subsequent study in healthy subjects, ${ }^{[20]}$ participants received once-daily doses of placebo or etamicastat $25,50,100,200,400$, or $600 \mathrm{mg}$ for 10 days. Etamicastat and BIA 5-961 maximum concentrations were achieved at 1-3 and 2-4 hours, respectively, after dosing. The $t_{1 / 2}$ values ranged from 18.1 to 25.7 hours for etamicastat and from 6.7 to 22.5 hours for BIA 5-961. Both etamicastat and BIA 5-961 showed linear pharmacokinetics. The extent of systemic exposure to etamicastat and BIA 5-961 increased in an approximately dose-proportional manner, and steady-state plasma concentrations were attained up to 9 days of dosing. Approximately $40 \%$ of the etamicastat dose was recovered in urine in the form of etamicastat and BIA 5-961.

$\mathrm{N}$-Acetyltransferase (NAT) is one of the major hepatic phase II enzymes involved in drug metabolism. Humans express two functional NAT isoforms - NAT1 and NAT2. ${ }^{[21]}$ Results from previous entry-into-man studies ${ }^{[19,20]}$ showed that the NAT2 phenotype (rapid or slow $\mathrm{N}$-acetylating ability) is a major source of interindividual variability in etamicastat pharmacokinetics. For NAT1, eight single nucleotide polymorphisms (SNPs) were analyzed $(190 \mathrm{c}>\mathrm{t}, 445 \mathrm{~g}>\mathrm{a}, 459 \mathrm{~g}>\mathrm{a}, 559 \mathrm{c}$ $>\mathrm{t}, 560 \mathrm{~g}>\mathrm{a}, 640 \mathrm{t}>\mathrm{g}, 1088 \mathrm{t}>\mathrm{a}$, and $1095 \mathrm{c}>\mathrm{a})$ and the corresponding genotypes were defined according to the literature. ${ }^{[22,23]}$ Subjects were classified NAT1 rapid (fast) acetylators if they carried the NAT $1 * 10$ (except NAT $1 * 10 / * 14$ ) or NAT $1 * 11$ alleles, normal acetylators if they carried the NAT $1 * 4$ or NAT $1 * 3$ alleles or the NAT $1 * 10 / * 14$ genotype, and poor (slow) acetylators if they carried the NAT $1 * 14$ (except NAT $1 * 10 / * 14)$ or NAT1 $* 17$ alleles. For NAT2, four coding SNPs were analyzed $(191 \mathrm{~g}>\mathrm{a}, 341 \mathrm{t}>\mathrm{c}$, $590 \mathrm{~g}>\mathrm{a}$, and $857 \mathrm{~g}>\mathrm{a}$ ) and the corresponding genotypes were defined according to the literature. ${ }^{[24,25]}$ Subjects were classified NAT2 rapid acetylators if they carried the NAT $2 * 4 / * 4$ allele, or the NAT $2 * 4 / * 5, \mathrm{NAT} 2 * 4 / * 6$ or NAT $2 * 4 / * 7$ genotype, and poor acetylators if they carried the NAT $2 * 5 / * 5$, NAT $2 * 6 / * 6$ or NAT $2 * 7 / * 7$ alleles, or the NAT $2 * 5 / * 6, \mathrm{NAT} 2 * 5 / * 7$ or NAT $2 * 6 / * 7$ genotype. The NAT $2 * 4$ allele encodes for a fully active enzyme and is considered the wild-type (rapid acetylator) allele. Although the NAT1 phenotype showed no relevant effect on etamicastat pharmacokinetics, the results of previous entry-into-man studies ${ }^{[19,20]}$ clearly demonstrated that the NAT2 phenotype had a marked effect on systemic exposure to etamicastat and BIA 5-961. The extent of systemic exposure to etamicastat in NAT2 poor acetylators was approximately twice that observed in rapid acetylators. Consistent with this finding, the area under the concentration-time curve (AUC) of the acetylated metabolite BIA 5-961 was markedly higher in NAT2 rapid acetylators compared with poor acetylators, confirming the involvement of NAT2 in the biotransformation of etamicastat into BIA 5-961.

Here, the results of an exploratory study aiming to investigate the effect of food on the pharmacokinetics of a single $200 \mathrm{mg}$ oral dose of etamicastat in healthy subjects are described.

\section{Subjects and Methods}

\section{Study Design}

This was a single-center (Biotrial SA, Rennes, France), open-label, randomized, two-way crossover study in 12 healthy male subjects. The random- 
ized, balanced, single-dose, two-treatment (fed vs fasting), two-period, two-sequence crossover design is a standard for studying the effects of food on drug bioavailability. ${ }^{[26]}$ The study consisted of two periods separated by a washout phase of $\geq 14$ days. During each study period, the volunteers randomly received a single $200 \mathrm{mg}$ oral dose of etamicastat following either a standard highfat and high-calorie content breakfast or 10 hours of fasting.

During each treatment period, eligible subjects were admitted to the research facilities on the day (day 0) prior to receiving the dose of study medication for assessment of vital signs, medical history, and physical examination, in addition to screen tests for hematology, plasma biochemistry, and drug and alcohol abuse. At the beginning of the first treatment period, the subjects had a review of the selection criteria and a randomization number was assigned. The randomization number defined the treatment sequence to which each subject was allocated. On the morning of day 1 , etamicastat was administered following a standard high-fat and high-calorie meal in one treatment period, or following at least 10 hours of fasting in another treatment period. Participants remained confined in the research facilities from admission (day 0) until at least 72 hours (day 4, discharge) after dosing. Following the 72 hours post-dose procedures, participants were discharged, and returned for the next treatment period or a followup visit. Following administration of etamicastat (four capsules, $50 \mathrm{mg}$ ) with $240 \mathrm{~mL}$ of water, in fasting or fed conditions, a lunch, a snack, and a dinner were provided at respectively 4,8 , and 12 hours post-dose. Water ad libitum was allowed.

The standard high-fat and high-calorie content meal was composed of two scrambled eggs, fried fat bacon $(40 \mathrm{~g})$, white bread $(60 \mathrm{~g})$, corn flakes $(20 \mathrm{~g})$, whole milk ( $3 \%$ fat, $250 \mathrm{~mL}$ ), and butter $(80 \%$ fat, $15 \mathrm{~g})$. A total of approximately $933 \mathrm{kcal}$ was eaten $(167 \mathrm{kcal}$ as proteins, $527 \mathrm{kcal}$ as lipids, and $239 \mathrm{kcal}$ as carbohydrates). The breakfast was eaten within 30 minutes and drug administration occurred immediately, thereafter.

The study was conducted according to the principles of the Declaration of Helsinki and the Good Clinical Practice guidelines. An Independent
Ethics Committee (CCP Ouest VI, Brest, France) reviewed and approved the study protocol and the subject information. Written informed consent was obtained for each subject prior to enrollment in the study.

\section{Subjects}

Twelve healthy male volunteers aged $18-45$ years with a body mass index (BMI) of $19-28 \mathrm{~kg} / \mathrm{m}^{2}$ participated in the study. Healthy condition was assessed on the basis of medical history, physical examination, electrocardiogram, and clinical laboratory safety tests (hematology, coagulation, plasma biochemistry, urinalysis, and hepatitis $\mathrm{B}$, hepatitis $\mathrm{C}$, and HIV serology). Tests for drug and alcohol abuse were performed at screening and each admission. No concomitant medication was allowed during the study, except if required for the treatment of adverse events. During the stays at the clinical research unit, a standard diet was served, and alcohol-, caffeine- and grapefruit-containing food and beverages were prohibited.

\section{Assessment Procedures}

A complete medical history and physical examination were performed at screening and updated at each admission. Clinical adverse events were monitored throughout the entire study. Each adverse event was described in detail, including, onset time and date, offset time and date, description of occurrence, severity, relationship to investigational product, action taken, and outcome.

In each treatment period, blood samples $(7 \mathrm{~mL})$ for plasma assay of etamicastat and BIA 5-961 were taken at the following times: pre-dose, 0.5 , $1,2,3,4,5,6,8,10,12,16,24,48$, and 72 hours post-dose. Blood samples were drawn either by direct venepuncture or via an intravenous catheter into lithium-heparin Vacutainer ${ }^{\mathrm{TM}}$ tubes (Becton Dickinson UK Ltd, Oxford, UK) and centrifuged at approximately $1500 \mathrm{~g}$ for 10 minutes at $4^{\circ} \mathrm{C}$. The resulting plasma was separated into two aliquots of $750 \mu \mathrm{L}$ and stored at $-70^{\circ} \mathrm{C}$ until required for analysis.

Determination of plasma concentrations of etamicastat and its acetylated metabolite BIA 5-961 
was performed at Algorithme Pharma Inc. (Laval, QC, Canada) by liquid chromatography coupled to a mass spectrometry system using a previously validated method described elsewhere. ${ }^{[20]}$ Calibration curves, over the nominal concentration ranges $10-1000 \mathrm{ng} / \mathrm{mL}$, and a set of quality control samples (duplicates over five concentration levels) were analyzed with each batch of study samples. The quality control samples were used to monitor the performance of the assay. The data from the quality control samples showed that the overall imprecision of the method, measured by the coefficient of variation, ranged from $8.2 \%$ to $11.2 \%$ for etamicastat and from $4.6 \%$ to $10.6 \%$ for BIA 5-961. The overall accuracy, measured as the proportion of the determined value in relation to the true or nominal value, ranged from $95.0 \%$ to $105.0 \%$ for etamicastat and from $96.4 \%$ to $103.4 \%$ for BIA 5-961. The lower limit of quantification of the assay (LLOQ) was $10 \mathrm{ng} / \mathrm{mL}$.

\section{Pharmacokinetic Analysis}

The following pharmacokinetic parameters for etamicastat and BIA 5-961 were derived by non-compartmental analysis from the individual plasma concentration versus time profiles: maximum observed plasma drug concentration $\left(\mathrm{C}_{\max }\right)$; the time of occurrence of $\mathrm{C}_{\max }\left(\mathrm{t}_{\max }\right)$; area under the plasma concentration-time curve (AUC) from time zero to the last measurable concentration $\left(\mathrm{AUC}_{\text {last }}\right)$ [calculated by the linear trapezoidal rule]; AUC from time zero to infinity $\left(\mathrm{AUC}_{\infty}\right)$ [calculated from $\mathrm{AUC}_{\text {last }}+\left(\mathrm{C}_{\text {last }} / \lambda_{\mathrm{z}}\right)$, where $C_{\text {last }}$ is the last quantifiable drug concentration]; and $t_{1 / 2}$ (calculated from $\ln 2 / \lambda_{z}$, where $\lambda_{z}$ is the apparent terminal rate constant calculated by log-linear regression of the terminal segment of the plasma concentration versus time curve).

Actual sampling times were used for the pharmacokinetic analysis. Special consideration was given to the estimation of $\lambda_{z}$ and corresponding $t_{1 / 2}$ values. Values of $\lambda_{z}$ were calculated from a minimum of three datapoints. Those $\lambda_{\mathrm{z}}$ values determined from three datapoints, and those values calculated over a period that was less than 2 -fold greater than the corresponding $t_{1 / 2}$ values were noted in the appropriate tables. Where an
AUC was extrapolated to infinity, the percentage of the extrapolated area to the total area was assessed, and if greater than $20 \%$, the AUC value was flagged as unreliable. Plasma concentrations below the LLOQ $(10 \mathrm{ng} / \mathrm{mL})$ of the assay were taken as zero for all calculations. Summary statistics of all data for each treatment and schedule sampling time were reported, as appropriate, using the geometric mean, arithmetic mean, standard deviation (SD), coefficient of variation $(\mathrm{CV})$, median, and range (minimum and maximum).

For the evaluation of the effect of food on etamicastat pharmacokinetics, the parameters $\mathrm{AUC}_{\infty}$, $A \mathrm{UC}_{\text {last }}$, and $\mathrm{C}_{\max }$ were the primary variables. The effect of food on the pharmacokinetics of etamicastat was studied in accordance with the statistical method for testing relative bioavailability (e.g. bioequivalence) in which $90 \%$ confidence intervals for the geometric mean ratio (GMR) [point estimate] of the observed pharmacokinetic parameters with food (fed $=$ test) and without food (fasting = reference) should be reported. For such purpose, the etamicastat pharmacokinetic parameters of interest $\left(\mathrm{AUC}_{\infty}, \mathrm{AUC}_{\text {last }}\right.$, and $\mathrm{C}_{\max }$ ) were compared using ANOVA. The test procedure was analogous to equivalence testing. ANOVA was used to test for differences between test (fed condition) and reference (fasting condition) for $\mathrm{AUC}_{\infty}, \mathrm{AUC}_{\text {last }}$, and $\mathrm{C}_{\max }$ of etamicastat. The pharmacokinetic parameters were logarithmically transformed prior to analysis. The $90 \%$ confidence intervals (CIs) for the GMR of etamicastat and BIA 5-961 $\mathrm{AUC}_{\infty}, \mathrm{AUC}_{\text {last }}$, and $\mathrm{C}_{\max }$ were constructed, comparing test versus reference treatments. In accordance with the guidelines for bioequivalence testing, the bioequivalence was assumed when the $90 \% \mathrm{CI}$ for the test/ reference GMR fell within the usually accepted reference interval $(80,125) \cdot{ }^{[27-29]}$ The Wilcoxon signed rank test was used to test for the difference in $t_{\max }$ (secondary variable) between test and reference treatments. An $\alpha$-level of 0.05 was used for defining statistical significance.

No results of previous studies in humans were known at the time of defining the study design. A sample size of 12 evaluable subjects was defined for this study because it is the minimum sample size required by the current regulatory guidance. ${ }^{[29]}$ 
The post hoc power for the current study was calculated as $96.29 \%$ for etamicastat $C_{\max }, 99.99 \%$ for etamicastat $\mathrm{AUC}_{\text {last }}$, and $99.99 \%$ for etamicastat $\mathrm{AUC}_{\infty}$.

The pharmacokinetic parameters were determined using WinNonlin ${ }^{\circledR}$ Version 5.2 (Pharsight Inc, Mountain View, CA, USA). The statistical package SAS $^{\circledR}$ Version 9.1 (SAS Institute Inc, Cary, NC, USA) was used in computations.

\section{Tolerability Analysis}

Adverse events were coded according to the Medical Dictionary for Regulatory Activities (MedDRA, version 12.0). Individual and summary blood pressure, heart rate, and clinical laboratory data were presented in tabular form with mean, $\mathrm{SD}$, median, and range, as appropriate. For the laboratory safety data, out of range values were flagged in the data listings and a list of clinically significantly abnormal values was presented.

\section{Results}

\section{Population}

A total of 12 male subjects were enrolled in and completed the study. The mean \pm SD demographic data were as follows: age $26.9 \pm 5.5$ (range 19-34) years; height $176 \pm 7$ (range 164-186) cm; weight $73.8 \pm 10.5$ (range $55-93$ ) $\mathrm{kg}$; and BMI $23.7 \pm 2.1$ (range $20.0-27.0) \mathrm{kg} / \mathrm{m}^{2}$. All subjects were Caucasian.

\section{Pharmacokinetic Results}

Mean plasma etamicastat and BIA 5-961 concentration versus time profiles and corresponding pharmacokinetic parameters following a single oral $200 \mathrm{mg}$ dose of etamicastat in fasting and fed conditions are presented in figure 1 and table I. All pharmacokinetic parameters could be reliably estimated.

Etamicastat $\mathrm{C}_{\max }$ was reached between 1 and 2 hours post-dose in the fasting group, after which concentrations declined with an approximate mean apparent terminal $t_{1 / 2}$ of 19.9 hours. Following the standard meal, etamicastat $\mathrm{C}_{\max }$ was reached between 2 and 5 hours post-dose, and $t_{1 / 2}$ was 19.6 hours. GMR and $90 \%$ CI for the etamicastat pharmacokinetic parameters of interest $\left(\mathrm{AUC}_{\infty}, \mathrm{AUC}_{\text {last }}\right.$, and $\left.\mathrm{C}_{\max }\right)$ are given in table II. The extent of exposure of etamicastat, as reflected by $\mathrm{AUC}_{\text {last }}$ and $\mathrm{AUC}_{\infty}$, fulfilled the claim of bioequivalence because the $90 \%$ CI fell within the reference range $(80,125)$; however, the exposure to etamicastat, as reflected by $\mathrm{C}_{\max }$, did not fit the claim of bioequivalence between test (fed) and reference (fasting), because the $90 \% \mathrm{CI}$ fell outside the reference range. Etamicastat $\mathrm{C}_{\max }$ decreased $28 \%$ as a result of food intake. Etamicastat $t_{\max }$ was significantly delayed following administration of etamicastat in the fed condition compared with administration in the fasting group $(\mathrm{p}<0.001)$.

BIA 5-961 GMR and 90\% CI showed a significant decrease of BIA 5-961 $\mathrm{AUC}_{\infty}, \mathrm{AUC}_{\text {last }}$, and

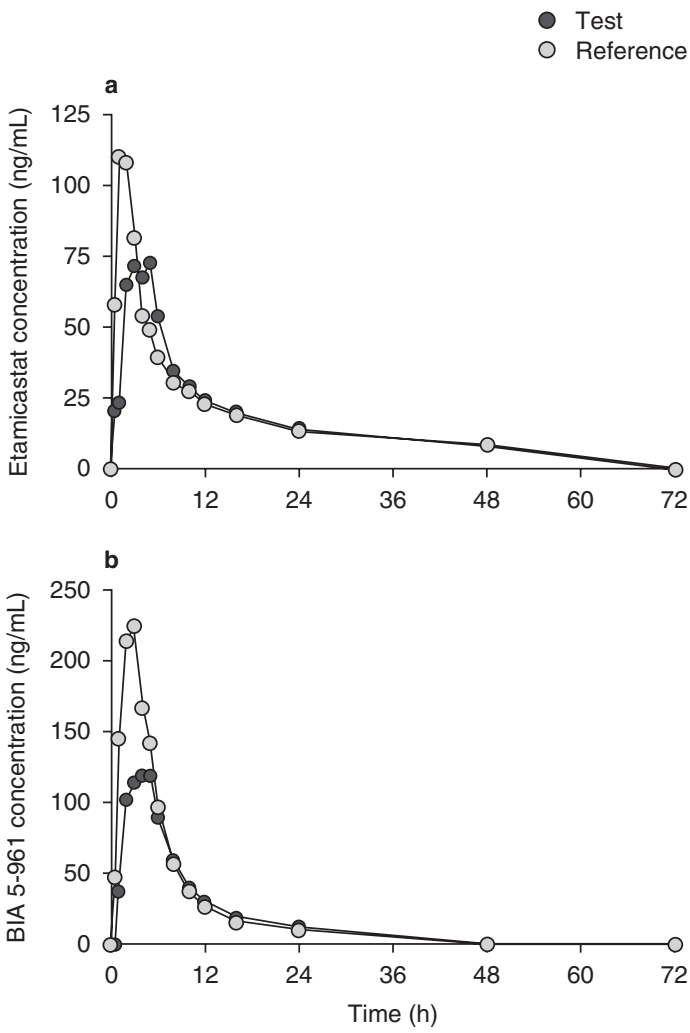

Fig. 1. Mean plasma concentration vs time profiles of (a) etamicastat and (b) BIA 5-961 following a single oral dose of etamicastat $200 \mathrm{mg}$ in fasting (reference) and fed (test) conditions $(n=12)$. 
Table I. Pharmacokinetic parameters of etamicastat and BIA 5-961 following a single oral dose of etamicastat $200 \mathrm{mg}$ in fasting (reference) and fed (test) conditions $(n=12)$

\begin{tabular}{|c|c|c|c|c|c|c|c|}
\hline $\begin{array}{l}\text { Analyte/ } \\
\text { condition }\end{array}$ & Statistics & $\begin{array}{l}\mathrm{C}_{\max } \\
(\mathrm{ng} / \mathrm{mL})\end{array}$ & $\begin{array}{l}t_{\max } \\
\text { (h) }\end{array}$ & $\begin{array}{l}A \cup C_{\text {last }} \\
(n g \bullet h / m L)\end{array}$ & $\begin{array}{l}\mathrm{AUC}_{\infty} \\
(\mathrm{ng} \bullet \mathrm{h} / \mathrm{mL})\end{array}$ & $\begin{array}{l}\lambda_{\mathrm{z}} \\
(\mathrm{L} / \mathrm{h})\end{array}$ & $\begin{array}{l}t_{1 / 2} \\
\text { (h) }\end{array}$ \\
\hline \multicolumn{8}{|c|}{ Etamicastat } \\
\hline \multirow[t]{2}{*}{ Fasting } & AMean \pm SD & $229 \pm 48$ & $1.5 \pm 0.5$ & $1856 \pm 818$ & $2238 \pm 943$ & $0.0416 \pm 0.0197$ & $19.9 \pm 8.2$ \\
\hline & GMean (median) & $224(227)$ & $1.4(1.5)$ & $1659(2287)$ & $2022(2828)$ & $0.0379(0.0364)$ & $18.3(19.1)$ \\
\hline \multirow[t]{2}{*}{ Fed } & AMean \pm SD & $166 \pm 37$ & $3.5 \pm 1.2$ & $1737 \pm 794$ & $2119 \pm 849$ & $0.0391 \pm 0.0132$ & $19.6 \pm 6.3$ \\
\hline & GMean (median) & $162(169)$ & $3.3(3.0)$ & 1553 (1957) & $1951(2314)$ & $0.0372(0.0390)$ & $18.7(17.8)$ \\
\hline \multicolumn{8}{|c|}{ BIA 5-961 } \\
\hline \multirow[t]{2}{*}{ Fasting } & AMean \pm SD & $384 \pm 311$ & $2.7 \pm 0.5$ & $2396 \pm 1802$ & $2559 \pm 1836$ & $0.1100 \pm 0.0474$ & $8.0 \pm 4.6$ \\
\hline & GMean (median) & $275(186)$ & $2.6(3.0)$ & $1827(1189)$ & 2009 (1326) & $0.0987(0.1200)$ & $7.0(5.8)$ \\
\hline \multirow[t]{2}{*}{ Fed } & AMean \pm SD & $228 \pm 173$ & $4.1 \pm 1.2$ & $1840 \pm 1332$ & $2051 \pm 1375$ & $0.0854 \pm 0.0323$ & $9.1 \pm 3.0$ \\
\hline & GMean (median) & $172(110)$ & $3.9(5.0)$ & $1450(991)$ & 1677 (1225) & $0.0804(0.0801)$ & $8.6(8.7)$ \\
\hline
\end{tabular}

$\lambda_{\mathbf{z}}=$ apparent terminal rate constant; $\mathbf{A M e a n}=$ arithmetic mean; $\mathbf{A} \mathbf{U C}_{\infty}=$ area under the concentration-time curve from time zero to infinity; $\mathbf{A U C}_{\text {last }}=$ area under the plasma concentration-time curve from time zero to the last measurable concentration; $\mathbf{C}_{\max }=$ maximum plasma concentration; $\mathbf{G M e a n}=$ geometric mean; $\mathbf{t}_{1 / 2}=$ elimination half life; $\mathbf{t}_{\max }=$ time to $C_{\max }$.

$\mathrm{C}_{\max }$ when etamicastat was administered in the presence of food (table II). No statistical difference on BIA 5-961 $\mathrm{t}_{\max }(\mathrm{p}<0.05)$ following administration of etamicastat in the fasting or fed condition was found.

Figure 2 displays the individual etamicastat and BIA 5-961 $\mathrm{C}_{\max }$ and $\mathrm{AUC}_{\infty}$ pharmacokinetic parameters. From figure 2, it is apparent that the subgroup of five subjects (\#03, \#04, \#06, \#07, and $\# 08$ ) who showed the lowest etamicastat $\mathrm{AUC}_{\infty}$ values following administration of etamicastat also showed the highest BIA 5-961 $\mathrm{C}_{\max }$ values. These subjects probably presented a NAT2 rapid acetylating phenotype, leading to faster biotransformation of etamicastat into its acetylated metabolite BIA 5-961.

\section{Tolerability Results}

During the course of the study, 4 (33.3\%) of 12 subjects who constituted the safety population reported a total of six treatment-emergent adverse events (TEAEs). Two TEAEs (headache and vagal reaction) were reported during the fasting period, and four TEAEs during the fed period (abdominal pain, asthenia, headache, and intercostal pain). All TEAEs were mild to moderate in intensity. There were no serious adverse events or discontinuations due to adverse events. No clinically relevant abnormalities were ob- served in vital signs, ECG, or laboratory safety tests during the study.

\section{Discussion}

The primary objective of the study was to investigate the effect of food on the pharmacokinetics of etamicastat. $\mathrm{C}_{\max }, \mathrm{AUC}_{\text {last }}$, and $\mathrm{AUC}_{\infty}$ of etamicastat were defined as the main parameters for the assessment of bioavailability and bioequivalence of etamicastat administered in fasting and fed conditions, which is in agreement with current

Table II. Test/reference geometric means ratio (GMR) and $90 \% \mathrm{Cl}$ of etamicastat and BIA 5-961 maximum plasma concentration $\left(C_{\text {max }}\right)$, area under the concentration-time curve (AUC) from time zero to the last measurable concentration $\left(A \cup C_{\text {last }}\right)$, and $A \cup C$ from time zero to infinity $\left(A \cup C_{\infty}\right)$ following a single oral dose of etamicastat $200 \mathrm{mg}$ in fasting (reference) and fed (test) conditions $(n=12)$

\begin{tabular}{lll}
\hline Parameter & Etamicastat & BIA 5-961 \\
\hline $\mathbf{C}_{\max }$ & & \\
GMR (\%) & 72.27 & 62.42 \\
$90 \% \mathrm{Cl}$ & $64.98,80.38$ & $56.77,68.63$ \\
AUC $_{\text {Iast }}$ & & \\
GMR (\%) & 93.59 & 79.41 \\
$90 \% \mathrm{Cl}$ & $89.28,98.11$ & $56.77,68.63$ \\
AUC $_{\infty}$ & & \\
GMR (\%) & 96.47 & 83.47 \\
$90 \% \mathrm{Cl}$ & $91.67,101.53$ & $76.62,90.93$ \\
\hline
\end{tabular}



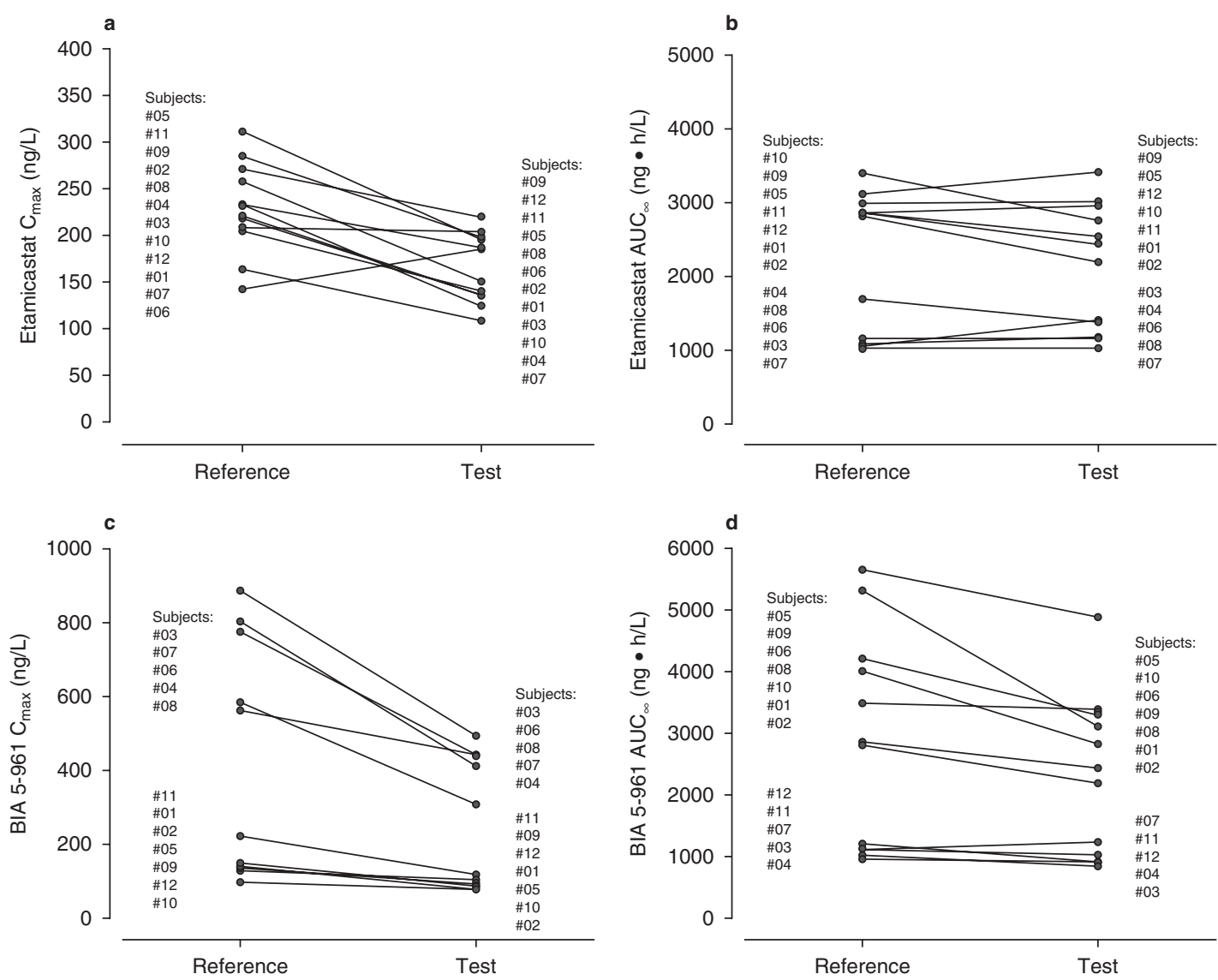

Fig. 2. Individual mean etamicastat (a) maximum plasma concentration $\left(C_{\max }\right)$ and (b) area under the concentration-time curve from time zero to infinity $\left(A \cup C_{\infty}\right)$; and BIA 5-961 (c) $C_{\max }$ and (d) $A U C_{\infty}$ values following a single oral dose of etamicastat 200 mg in fasting (reference) and fed (test) conditions $(n=12)$.

regulatory guidelines. ${ }^{[26,30]}$ The $90 \%$ CI for the fed/fasting etamicastat $\mathrm{C}_{\max }$ GMR are not contained within the acceptance interval $(80,125)^{[27,28]}$ and, therefore, it can be concluded that the rate of systemic exposure to etamicastat does not fit the claim of bioequivalence between administration in fasting and fed conditions. Etamicastat $\mathrm{C}_{\max }$ significantly decreased by $28 \%$ and $\mathrm{t}_{\max }$ significantly increased, but $\mathrm{AUC}_{\text {last }}$ and $\mathrm{AUC}_{\infty}$ remained within the acceptance interval, showing that the extent of systemic exposure to etamicastat was not affected by the delay in absorption of etamicastat in the presence of food. Although a significant decrease in $\mathrm{C}_{\max }$ is not expected to have an impact on the tolerability of a drug, it could have a hypothetical impact on efficacy. However, the inhibition of $\mathrm{D} \beta \mathrm{H}$ by $\mathrm{D} \beta \mathrm{H}$ blockers provides gradual sympathetic modulation as opposed to abrupt inhibition; ${ }^{[8]}$ therefore, a delay in absorption and corresponding decrease in peak exposure without a relevant change in the extent of exposure (AUC) is not expected to be clinically significant.

Etamicastat appeared to be metabolized to its acetylated metabolite BIA 5-961, which is in agreement with other studies. ${ }^{[19,20]}$ Systemic exposure to the metabolite BIA 5-961 decreased as a result of food. However, this effect is not expected to have an impact on etamicastat tolerability or efficacy since the metabolite is inactive. 
The pharmacokinetic results of the current study are consistent with those of the $200 \mathrm{mg}$ dose group of an entry-into-man study ${ }^{[19]}$ in healthy subjects administered with single oral doses of etamicastat ranging from 2 to $1200 \mathrm{mg}$ in fasting conditions. In the earlier study, ${ }^{[19]}$ arithmetic mean etamicastat $\mathrm{C}_{\max }$ was $202 \mathrm{ng} / \mathrm{mL}, \mathrm{AUC}_{\text {last }}$ was $2026 \mathrm{ng} \bullet \mathrm{h} / \mathrm{mL}, \mathrm{AUC}_{\infty}$ was $2230 \mathrm{ng} \bullet \mathrm{h} / \mathrm{mL}$, and $t_{1 / 2}$ was 19.8 hours following a $200 \mathrm{mg}$ single dose in a fasting condition; these results are close to those reported in the fasting period of the current study $(229 \mathrm{ng} / \mathrm{mL}, 1856 \mathrm{ng} \bullet \mathrm{h} / \mathrm{mL}, 2238 \mathrm{ng} \bullet \mathrm{h} / \mathrm{mL}$, and 19.9 hours, respectively).

The results of the current study show a large interindividual variability in the pharmacokinetic parameters of interest in both analytes (etamicastat and its metabolite) and in both study periods. This interindividual variability is consistent with that reported in previous studies ${ }^{[19,20]}$ and is likely to be as a result of differences in NAT2 genotype, leading to different acetylating profiles. The clinical consequence is that NAT2 genotyping may be required for an adequate dosage definition of etamicastat in patients. Etamicastat was well tolerated in both study periods.

\section{Conclusion}

This exploratory study involving administration of etamicastat to healthy volunteers under fasting conditions and with a high-fat meal indicated that etamicastat $\mathrm{C}_{\max }$ was decreased $28 \%$, while AUC remained unchanged. This decrease in peak exposure is not clinically significant, and therefore etamicastat can be taken with or without meals.

\section{Acknowledgments}

This study was financially supported by BIAL-Portela \& Co., SA, S. Mamede do Coronado, Portugal.

The authors from BIAL substantially contributed to the design and conception of the study. All authors had full access to the data and substantially contributed to the interpretation of the data and the writing of the manuscript.

MVS, TN, JFR, LA, and PSS were employees of BIAL (the sponsor of the study) at the time of the study. AF was an employee of a contract research organization contracted by the sponsor to review the pharmacokinetic data (4Health Ltd).

\section{References}

1. Esler M, Kaye D. Sympathetic nervous system activation in essential hypertension, cardiac failure and psychosomatic heart disease. J Cardiovasc Pharmacol 2000; 35 (7 Suppl. 4): S1-7

2. Grassi G, Bolla G, Quarti-Trevano F, et al. Sympathetic activation in congestive heart failure: reproducibility of neuroadrenergic markers. Eur J Heart Fail 2008 Dec; 10 (12): 1186-91

3. Grassi G, Seravalle G, Quarti-Trevano F. The 'neuroadrenergic hypothesis' in hypertension: current evidence. Exp Physiol 2010; 95 (5): 581-6

4. Lee CS, Tkacs NC. Current concepts of neurohormonal activation in heart failure: mediators and mechanisms. AACN Adv Crit Care 2008 Oct-Dec; 19 (4): 364-85

5. Mancia G, Grassi G, Giannattasio C, et al. Sympathetic activation in the pathogenesis of hypertension and progression of organ damage. Hypertension 1999; 34 (4 Pt 2): 724-8

6. Parmley WW. Neuroendocrine changes in heart failure and their clinical relevance. Clin Cardiol 1995; 18 (8): 440-5

7. Pfeffer MA, Stevenson LW. Beta-adrenergic blockers and survival in heart failure. N Engl J Med 1996; 334 (21): 1396-7

8. Stanley WC, Li B, Bonhaus DW, et al. Catecholamine modulatory effects of nepicastat (RS-25560-197), a novel, potent and selective inhibitor of dopamine-beta-hydroxylase. Br J Pharmacol 1997; 121 (8): 1803-9

9. Goldstein M, Anagnoste B, Lauber E, et al. Inhibition of dopamine-beta-hydroxylase by disulfiram. Life Sci 1964; 3 : 763-7

10. Lippmann W, Lloyd K. Dopamine-ß-hydroxylase inhibition by dimethyldithiocarbamate and related compounds. Biochem Pharmacol 1969; 18 (10): 2507-16

11. Hidaka H. Fusaric (5-butylpicolinic) acid, an inhibitor of dopamine beta-hydroxylase, affects serotonin and noradrenaline. Nature 1971; 231 (5297): 54-5

12. Johnson GA, Boukma SJ, Kim EG. In vivo inhibition of dopamine beta-hydroxylase by 1-phenyl-3-(2-thiazolyl)-2thiourea (U-14,624). J Pharmacol Exp Ther 1970; 171 (1): 80-7

13. Beliaev A, Learmonth DA, Soares-da-Silva P. Synthesis and biological evaluation of novel, peripherally selective chromanyl imidazolethione-based inhibitors of dopamine betahydroxylase. J Med Chem 2006; 49 (3): 1191-7

14. Igreja B, Wright L, Soares-da-Silva P. Sustained antihypertensive effects of a selective peripheral dopamineß-hydroxylase inhibitor [abstract]. Hypertension 2007; 50: e133

15. Igreja B, Wright L, Soares-da-Silva P. Long-term lowering of blood pressure levels in the SHR by selective peripheral inhibition of dopamine-b-hydroxylase with BIA 5-453 [abstract]. pA2 Online 2008; 6: 087P

16. Wright L, Soares-da-Silva P. Long-term benefits of the selective peripheral dopamine- $\beta$-hydroxylase inhibitor BIA 5-453 in heart failure [abstract]. pA2 Online 2008; 6: 088P

17. Data on file, BIAL, 2008

18. Igreja B, Loureiro AI, Fernandes-Lopes C, et al. Interspecies differences in pharmacodynamic and disposition of BIA 5-453, a novel dopamine- $\beta$-hydroxylase inhibitor [abstract]. Drug Metabol Rev 2009; 40 Suppl. 1: 39-40

19. Rocha JF, Vaz-da-Silva M, Nunes T, et al. Single-dose tolerability, pharmacokinetics and pharmacodynamics of 
etamicastat (BIA 5-453), a new dopamine ß-hydroxylase inhibitor, in healthy subjects. J Clin Pharmacol. Epub 2011 Feb 22

20. Nunes T, Rocha JF, Vaz-da-Silva M, et al. Safety, tolerability and pharmacokinetics of etamicastat, a novel dopamine$\beta$-hydroxylase inhibitor, in a rising multiple-dose study in young healthy subjects. Drugs R D 2010; 10 (4): 255-42

21. Winter HR, Unadkat JD. Identification of cytochrome P450 and arylamine $\mathrm{N}$-acetyltransferase isoforms involved in sulfadiazine metabolism. Drug Metab Dispos 2005; 33: 969-76

22. Fronhoffs S, Bruning T, Ortiz-Pallardo E, et al. Real-time PCR analysis of the N-acetyltransferase NAT1 allele *3, *4, $* 10, * 11, * 14$ and $* 17$ polymorphism in squamous cell cancer of head and neck. Carcinogenesis 2001 Sep; 22 (9): 1405-12

23. Li D, Jiao L, Li Y, et al. Polymorphisms of cytochrome P4501A2 and N-acetyltransferase genes, smoking, and risk of pancreatic cancer. Carcinogenesis 2006 Jan; 27 (1): 103-11

24. Brocvielle H, Muret P, Goydadin AC, et al. N-acetyltransferase 2 acetylation polymorphism: prevalence of slow acetylators does not differ between atopic dermatitis patients and healthy subjects. Skin Pharmacol Appl Skin Physiol 2003 Nov-Dec; 16 (6): 386-92

25. Rychlik-Sych M, Skretkowicz J, Gawronska-Szklarz B, et al. Acetylation genotype and phenotype in patients with systemic lupus erythematosus. Pharmacol Rep 2006 JanFeb; 58 (1): 22-9

26. FDA/CDER. Guidance for industry (draft). Food-effect bioavailability and fed bioequivalence studies. US Department of Health and Human Services, Food and Drug Administration, Center for Drug Evaluation and Research (CDER), 2002 [online]. Available from URL: http://www. fda.gov/downloads/RegulatoryInformation/Guidances/UCM 126833.pdf [Accessed 2011 Apr 11]
27. EMEA/CPMP. Note for guidance on the investigation of bioavailability and bioequivalence. CPMP/EWP/1401/98, European Agency for the Evaluation of Medicinal Products, Committee for Proprietary Medicinal Products (CPMP), 2001 [online]. Available from URL: http://www.ema.eur opa.eu/docs/en_GB/document_library/Scientific_guideline/ 2009/09/WC500003011.pdf [Accessed 2011 Apr 11]

28. FDA/CDER. Guidance for industry. Bioavailability and bioequivalence studies for orally administered drug products-general considerations. US Department of Health and Human Services, Food and Drug Administration, Center for Drug Evaluation and Research (CDER), 2003 [online]. Available from URL: http://www.fda.gov/downloads/Drugs/ GuidanceComplianceRegulatoryInformation/Guidances UCM070124.pdf [Accessed 2011 Apr 11]

29. FDA/CDER. Guidance for industry, Bioanalytical method validation. US Department of Health and Human Services, Food and Drug Administration. Center for Drug Evaluation and Research (CDER). Center for Veterinary Medicine, 2001 [online]. Available from URL: http://www.fda. gov/downloads/Drugs/GuidanceComplianceRegulatory Information/Guidances/UCM070107.pdf [Accessed 2011 Apr 11]

30. EMEA/CPMP. Note for guidance on the investigation of drug interactions. CPMP/EWP/560/95, European Agency for the Evaluation of Medicinal Products, Committee for Proprietary Medicinal Products (CPMP). 1997 [online]. Available from URL: http://www.tga.gov.au/docs/pdf/eu guide/ewp/056095en.pdf [Accessed 2011 Apr 11]

Correspondence: Professor Patricio Soares-da-Silva, Department of Research and Development, BIAL, À Av. da Siderurgia Nacional, 4745-457 S. Mamede do Coronado, Portugal.

E-mail: psoares.silva@bial.com 